\title{
Occurrence of endoparasites in domestic owned cats in Dhaka city
}

\author{
Aysha Aurin, Rimi Farhana Zaman and Hamida Khanum* \\ Department of Zoology, University of Dhaka, Dhaka 1000, Bangladesh. \\ *Corresponding author. Email: hamida_khanum@yahoo.com
}

Copyright (c) 2020 Aurin et al. This article remains permanently open access under the terms of the Creative Commons Attribution License 4.0, which permits unrestricted use, distribution, and reproduction in any medium, provided the original work is properly cited.

Received 12th April, 2020; Accepted 15th May, 2020

\begin{abstract}
Domestic cats can harbour a large range endoparasites, many of which have zoonotic potential. Because domestic owned cats (pet) have a very close contact with their owners, cats infested with such parasites can be a threat to human health. The objective of the present study is to investigate the occurrence of endoparasites in domestic owned cats and awareness of zoonotic diseases among the cat owners in Dhaka Metropolitan City. Coprological examination was carried out on 30 domestic owned cats and 26 cat owners. The cats aged between 1 month to 13 years. In the domestic owned cats, effects of age, sex, season, type of household, frequency of giving anti-helminthic medicine and outdoor access were observed. The overall prevalence of gastrointestinal parasites was $43.33 \%$ in the cats. A total of seven species of gastrointestinal parasites were identified from domestic owned cats, which were- Isospora felis (3.33\%), Toxoplasma gondii (6.67\%), Dipylidium caninum (13.33\%), Toxocara cati (20\%), Toxascaris leonina (3.33\%), Ancylostoma tubaeforme (3.33\%) and Ancylostoma spp. (6.67\%). Kittens had the highest prevalence (45.45\%) followed by adult $(44.44 \%)$ and young cats $(40 \%)$. Female cats $(58.82 \%)$ had higher prevalence than males $(23.08 \%)$ and it was statistically significant $(p \leq 0.05)$.
\end{abstract}

Keywords: Domestic owned cat, prevalence, intensity, parasites, zoonotic diseases.

\section{INTRODUCTION}

Pet animals, particularly cats and dogs, play an important role in societies worldwide. They are important companions in many households, contributing to children's physical, social and emotional development and their owners' well-being, especially in the elderly (Wong et al. 1999). The domestic cat (Felis silvestris catus) is one of the most popular pets all over the globe. According to IFAH Europe (The International Federation for Animal Health Europe), apart from stray cats, there are about 220 million cats throughout the world (Szwabe and Błaszkowska, 2017). The oldest archaeological evidence of cat taming was found in Crete dating back to approximately 9,500 B.P. and remains of cats have also been found from Jericho near the Jordan River dated to 8,700 B.P. (Vigne et al., 2004).

The most widely accepted theory of cat domestication states that cats essentially domesticated themselves. Cats usually live in solitude and keep their own territories, making them more attached to places than to people. Rather, the best inference is that people simply tolerated wildcats using human environments and pet cats gradually diverted from their wild relatives over time and space (Driscoll et al., 2009). Studies have suggested that both human and animal companions are benefited in many ways by the relationship between them (Bernstein, 2007). The relationship between human health and pet ownership has been studied from various perspectives, and there is evidence suggests that pets provide companionship and also probably provide psychological and physiological health benefits (McNicholas et al., 2005).

The risk rates for cardiovascular disease are significantly lower for both current and past cat owners than for non-cat owners (Qureshi et al., 2009). Several studies have found that owning and/or interacting with a pet has benefits for the individual, including mental health outcomes such as reduced anxiety and physical health outcomes such as 
improved physical activity and immune response (Kaye et al., 2007; Takkouche et al., 2008). In older adults, animals also provide a sense of comfort and social support (Krause-Parello, 2008). While animals offer significant benefits to our society, there are well-documented health risks associated with owning a pet. Household pets were found to play a direct role in the transmission of zoonosis (Traversa, 2012).

This close contact, however, can also increase the risk of exposure to infectious diseases, as pets have been involved in the transmission of more than 60 zoonotic agents (Macpherson, 2005). Some of these parasites cause diseases which can be serious under specific circumstances (Baneth et al., 2016). The increasing number of companion animals, including cats, poses serious problems for public health, veterinary and socioeconomic problems throughout the world (Szwabe and Błaszkowska, 2017).

Without veterinary care, domesticated free roaming cats in many countries can cause problems of public health and animal welfare concerns. Indeed, the majority of diseases can be controlled or prevented by the cat owners if they are sufficiently knowledgeable and have the resources to do so (Njuguna et al., 2017). Concerns about the public health hazards of pet ownership have recently increased significantly, and while many potentially zoonotic organisms are associated with cats, enteric pathogens are of particular concern (Beugnet et al., 2014, Giannelli et al., 2017).

Variety of factors affect the epidemiology of cat parasites, including geographical location, presence of veterinary care, habits of the local animal populations, and the season of the year (Yang and Liang, 2015). Epidemiological surveillance studies reported in different countries show that owned cats permitted to roam outside have high parasite frequencies. Specific hazard factors for endoparasite contamination featured in the ESCCAP (2017) guide includes opportunity to wander, contact with canines/felines outside the occupant family, eating flesh or excrement of conspecifics or eating prey. Additional considerations include animal age (e.g. more frequent deworming of puppies), pregnancy/ lactation status, eating slugs/snails, contact with children or immunocompromised persons (increased zoonotic risk) and travel to certain areas (e.g. endemic Echinococcus spp.) (McNamara et al., 2018).

Cats may harbor a large number of endoparasites, including protozoa, cestodes, trematodes and nematodes. Gastrointestinal species are considered to be the most important of all the parasites of cats from an epidemiological point of view. Cats have a wide range of helminth parasites, several of which are of zoonotic importance (Khalafalla, 2011). In addition to causing disease in cats, the parasites are of zoonotic importance (Yang and Liang, 2015). Cat-to-cat roundworm transmission usually occurs by oral or transmammary route, whereas hookworm transmission occurs by oral or cutaneous route and whipworm transmission by oral route.

However, depending on the parasite species and its abundance, infestations can also cause varying clinical signs in cats, such as lethargy, dull haircoat, vomiting, diarrhoea, poor growth rate, anaemia and sometimes even death, particularly in kittens. (Traversa, 2012, Duarte et al., 2016). Kittens and young animals typically have a higher prevalence of infections and associated clinical diseases (Riggio et al., 2013). However, adult and wild felids also contribute to pollution of the environment and hence to the maintenance of life cycles (Otranto et al., 2015).

Cats and other felines, can act as reservoirs, carriers, transmitters and definitive hosts for many intestinal parasites. These animals play an important role in parasite transmission to human and other animals by shedding parasitic eggs, larvae, cyst or oocyst in their feces (Mircean et al., 2010). Furthermore, these zoonotic parasites can transmit either by close contact with parasitized animals or by exposure to a contaminated environment (Deplazes et al., 2011).

Toxocara cati infections in free-roaming cat populations are of particular concern due to the public health risk and its neglected parasite infection status (Centers for Disease Control, 2016a). The infective stage larvae within egg of the feline roundworm, $T$. cati, persists for years in the environment and remains transmissible by accidental ingestion. This debilitating disease is most commonly associated with children playing in uncovered sandboxes or on beaches that free-roaming cats can use for a litter box. Transmission takes place through drinking water contaminated with infected copepods or consumption of undercooked 2nd intermediate hosts including amphibians, reptiles, and fish (Wyrosdick et al., 2017). Zoonotic cestodes from cats like Dipylidium caninum and Echinococcus multilocularis may also cause infection in humans. Toxoplasma gondii is of great importance in public health among protozoans.

Both Cryptosporidium and Giardia are immediately infective during host fecal shedding (Wyrosdick et al., 2017). Although cats may carry various zoonotic parasites, research shows that domestic owned cats are less affected by parasites than stray cats or cats from shelters, breeding kennels or pet shops. Thus, the prevalence of parasites in free-roaming cats is significantly higher than in household cats and, as a result, the free-roaming cat population is the main source of infection with parasites, especially in urban ecosystems (Hoopes et al., 2015).

\section{MATERIALS AND METHODS}

\section{Sample size}

Samples were collected from 30 domestic owned cats and 26 cat owners and among the pet cats, 23 were of local breed, 5 were of Persian breed and 2 were of mixed breed. Samples were collected from three different age groups 
from domestic owned cats and these are- Kitten (Age $\leq 1$ year), Young (Age 1year to 3 years), Adult (Age $\geq 3$ years). A self-administered questionnaire was developed in Bengali and English to record required data.

\section{Collection, examination and preservation of fecal sample}

About 20 to 25 grams of fresh fecal samples were collected from each cat owner and pet cats and each sample was kept in a plastic pot, carefully sealed and numbered. The samples were preserved in $10 \%$ formalin. To detect the presence of parasites egg and ova, Formol-Ether Concentration Technique was applied. Microscopic examination was used to identify the ova, oocysts and cysts of different parasites.

\section{Formol-ether concentration technique}

Formol-ether concentration technique is recommended as the best of overall techniques for the concentration of parasites in feces (Cheesbrough, 1987). Both protozoans and helminths present in fecal sample can be observed by this technique. Parasite's eggs, larvae and cysts present in feces can also be examined by this technique.

\section{Identification of different gastrointestinal parasites}

Identification of eggs, oocysts and cysts of different gastrointestinal helminth parasites were performed with the help of a compound microscope. Eggs, oocysts and cysts observed under the microscope were identified by following descriptions, life cycles and pictures published by Chatterjee (1975), Soulsby (1982), Cheesbrough (1987), Tropical Council for Companion Animal Parasites (TroCCAP) and Wikipedia.

\section{Data analyses}

Prevalence rates were calculated as the ratio of the number of positive animals to the total number of examined animals. Significant test was done by standard software (SPSS, version 25.0, SPSS Inc., Chicago, III) and values of $p \leq 0.05$ were considered significant.

\section{RESULTS}

In the present observation, out of 30 domestic owned cats, 13 were infected by different species of parasites. Among these 13 cats, 4 were infected by more than one species of parasite. Total seven species of parasites were found. Among them Toxocara cati had the highest prevalence $(20 \%)$. Other parasites which had high prevalence wereDipylidium caninum (13.33\%), Ancylostoma spp. (6.67\%) and Toxoplasma gondii (6.67\%). Toxocara cati also had the highest intensity rate $(102.33 \pm 101.61)$. Other parasites which had high intensity rate were- Toxascaris leonina $(98 \pm 17.89)$ and Dipylidium caninum (8.5 \pm 3.18$)$ (Table 1 and Figure 1).

\section{Prevalence}

Among the three age groups, Isospora felis (9.09\%), Toxoplasma gondii (18.18\%), Toxascaris leonina (9.09\%) and Ancylostoma tubaeforme (9.09\%) had the highest prevalence in kittens, but was not found in the other two age groups. Toxocara cati had somewhat similar prevalence in the three age groups, showing highest prevalence among young cats $(30 \%)$, followed by kittens (18.18\%) and adult cats (11.11\%). Ancylostoma spp. (20\%) was found in young cats, but was not found in the other two age groups. Dipylidium caninum (33.33\%) showed the highest prevalence in adult cats, followed by young cats $(10 \%)$ and was not found in kittens (Figure 2).

\section{Intensity}

The intensity rate of Toxocara cati $(558 \pm 186.0)$ in adult cats was the highest among all the parasites in the three age groups, followed by the intensity rate of Toxascaris leonina among kittens $(98 \pm 29.55)$. All the other gastrointestinal parasites found in the three age groups had a small intensity rate compared to these (Figure 3 ).

The sex of host might have an impact on parasitic infection in pet cats. That is why in the present study, sex of pet cats was included as a factor. A total of 13 males and 17 females were examined. Among them 3 males $(23.08 \%)$ and 10 females (58.82\%) were infected. The prevalence of parasites was statistically significant for domestic owned cats based on sex $(p=0.05$, since $p \leq$ $0.05)$. Intensity rate was higher in females $(73.2 \pm 137.49)$ than in male cats $(12 \pm 5.58)$ (Table 2 ).

Among 13 male pet cats, only 3 were infested $(23.08 \%)$ by gastrointestinal parasites. Dipylidium caninum had the highest prevalence (15.38\%) and Toxocara cati, Ancylostoma tubaeforme both had a prevalence of $7.69 \%$. Toxocara cati $(13 \pm 3.61)$ had the highest intensity rate and Ancylostoma tubaeforme showed the lowest intensity rate (3 \pm 0.83$)$ (Figure 4).

Among 17 female pet cats, 10 were infested (58.82\%) by gastrointestinal parasites. Toxocara cati had the highest prevalence (29.41\%). Isospora felis and Toxascaris leonina had the lowest prevalence (5.88\%). Toxocara cati $(120.2 \pm 134.76)$ had the highest intensity rate and Isospora felis showed the lowest intensity rate $(2 \pm 0.48)$ (Figure 5).

A total of 30 samples from domestic owned cats had been collected randomly from three seasons. These seasons were- summer, monsoon and winter. In summer 8 samples, 10 samples in monsoon and 12 in winter had 
Table 1. Prevalence and intensity of different parasites in domestic cats.

\begin{tabular}{lccccc}
\hline Name of the parasites & $\begin{array}{c}\text { Total no. of } \\
\text { host }\end{array}$ & $\begin{array}{c}\text { No. of } \\
\text { infected host }\end{array}$ & $\begin{array}{c}\text { Prevalence in } \\
\text { hosts (\%) }\end{array}$ & EPG/ CPG & Intensity \pm SD \\
\hline Isospora felis & 30 & 1 & 3.33 & 2 & $2 \pm 0.36$ \\
Toxoplasma gondii & 30 & 2 & 6.67 & 11 & $5.5 \pm 1.45$ \\
Dipylidium caninum & 30 & 4 & 13.33 & 35 & $8.5 \pm 3.18$ \\
Toxocara cati & 30 & 6 & 20 & 614 & $102.33 \pm 101.61$ \\
Toxascaris leonina & 30 & 1 & 3.33 & 98 & $98 \pm 17.89$ \\
Ancylostoma tubaeforme & 30 & 1 & 3.33 & 3 & $3 \pm 0.56$ \\
Ancylostoma spp. & 30 & 2 & 6.67 & 5 & $2.5 \pm 0.66$ \\
\hline
\end{tabular}

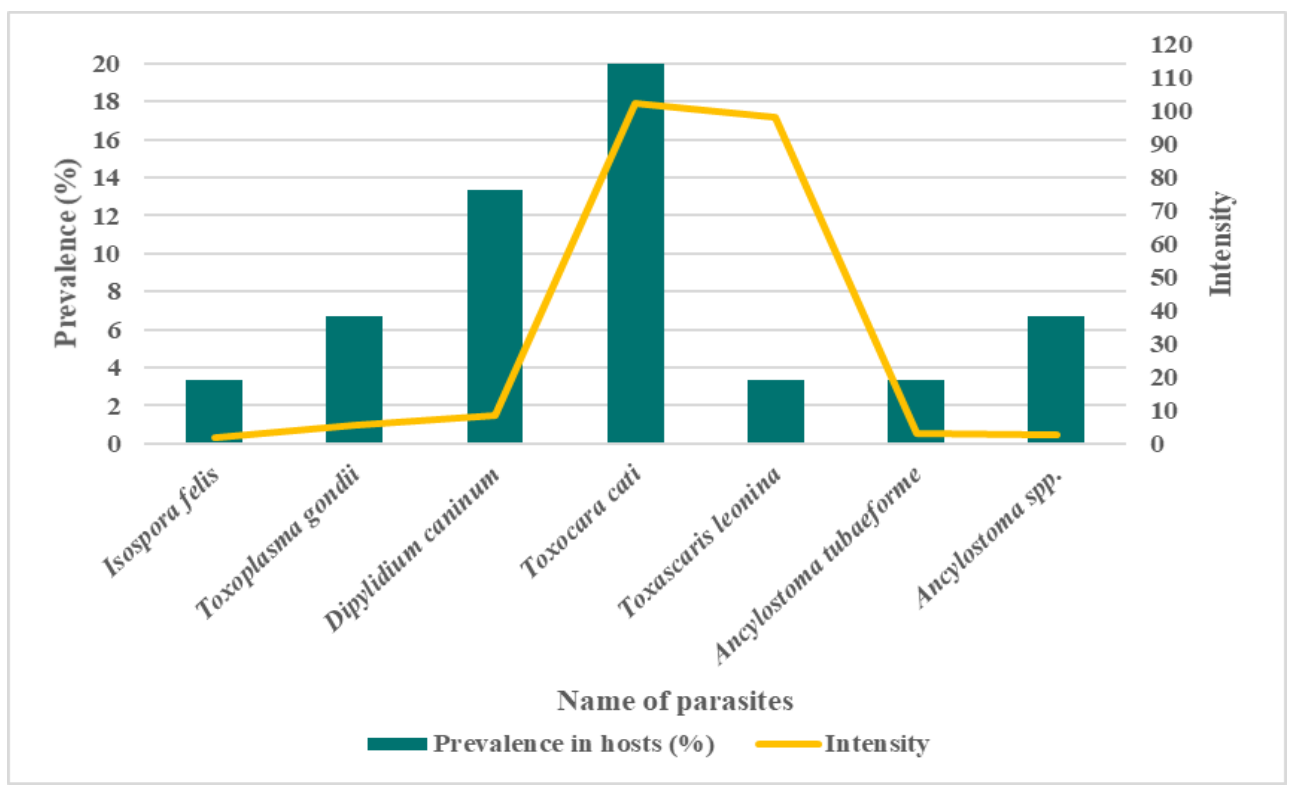

Figure 1. Prevalence and intensity of parasites in domestic owned cats.

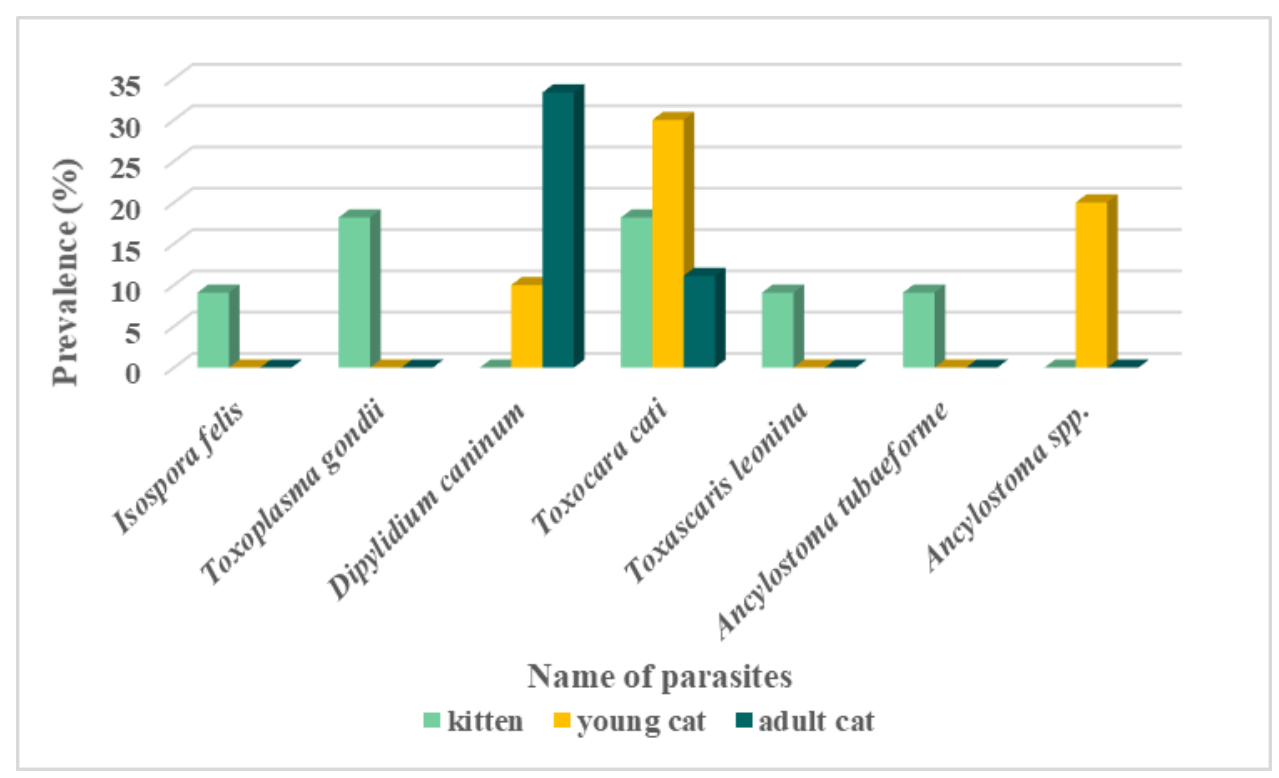

Figure 2. Age related prevalence of different parasite species in pet cats. 


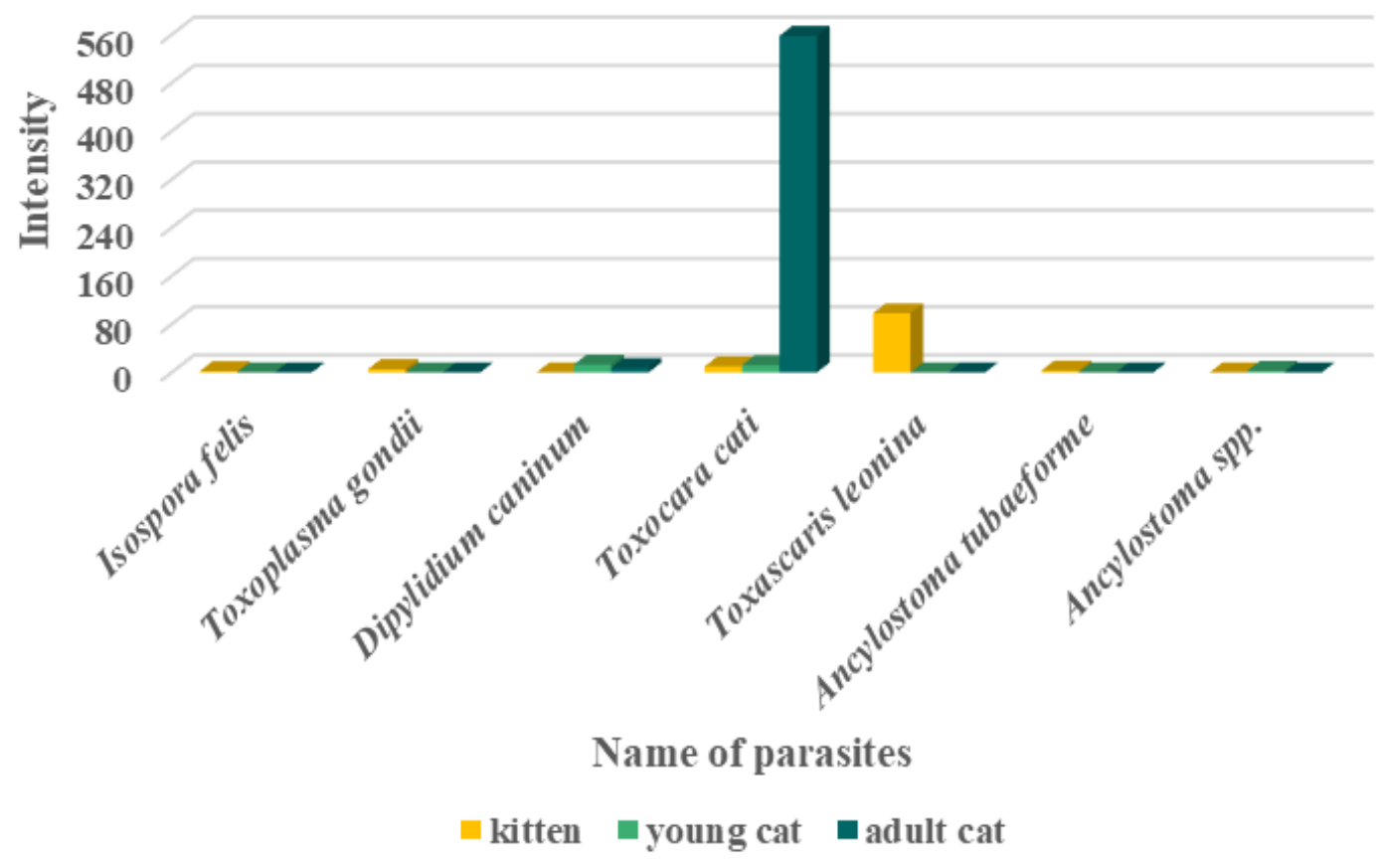

Figure 3. Age related intensity of different parasite in pet cats.

Table 2. Prevalence and intensity of parasites in relation to sex of domestic cats.

\begin{tabular}{lcccccc}
\hline $\begin{array}{l}\text { Sex of } \\
\text { hosts }\end{array}$ & $\begin{array}{c}\text { Total no. of } \\
\text { host }\end{array}$ & $\begin{array}{c}\text { No. of host } \\
\text { infected }\end{array}$ & $\begin{array}{c}\text { Prevalence in } \\
\text { hosts (\%) }\end{array}$ & EPG/ CPG & Intensity \pm SD & P value \\
\hline Male & 13 & 3 & 23.08 & 36 & $12 \pm 5.58$ & 0.05 \\
Female & 17 & 10 & 58.82 & 732 & $73.2 \pm 137.49$ & \\
\hline
\end{tabular}

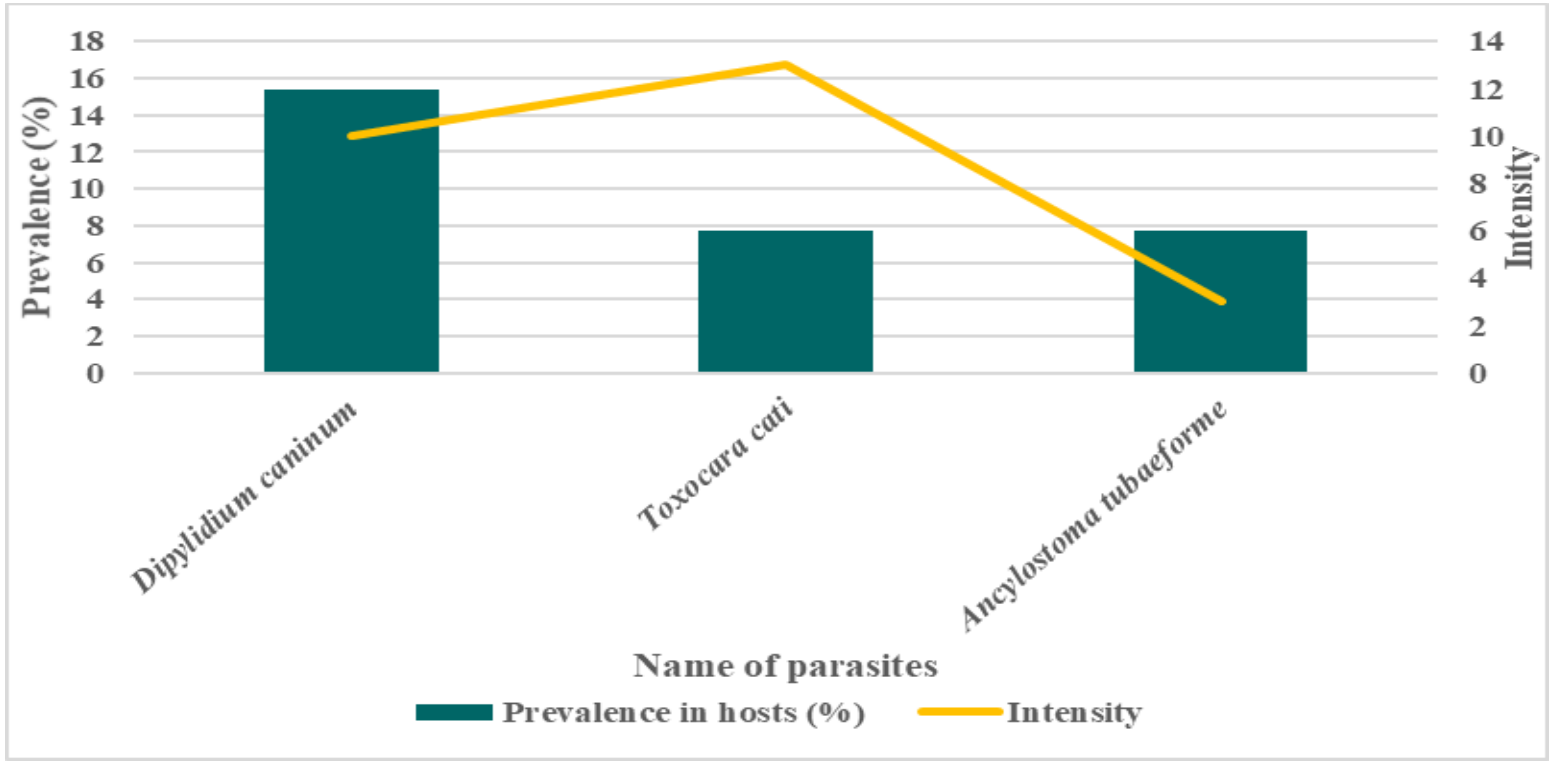

Figure 4. Prevalence and intensity of gastrointestinal parasites in male pet cats. 


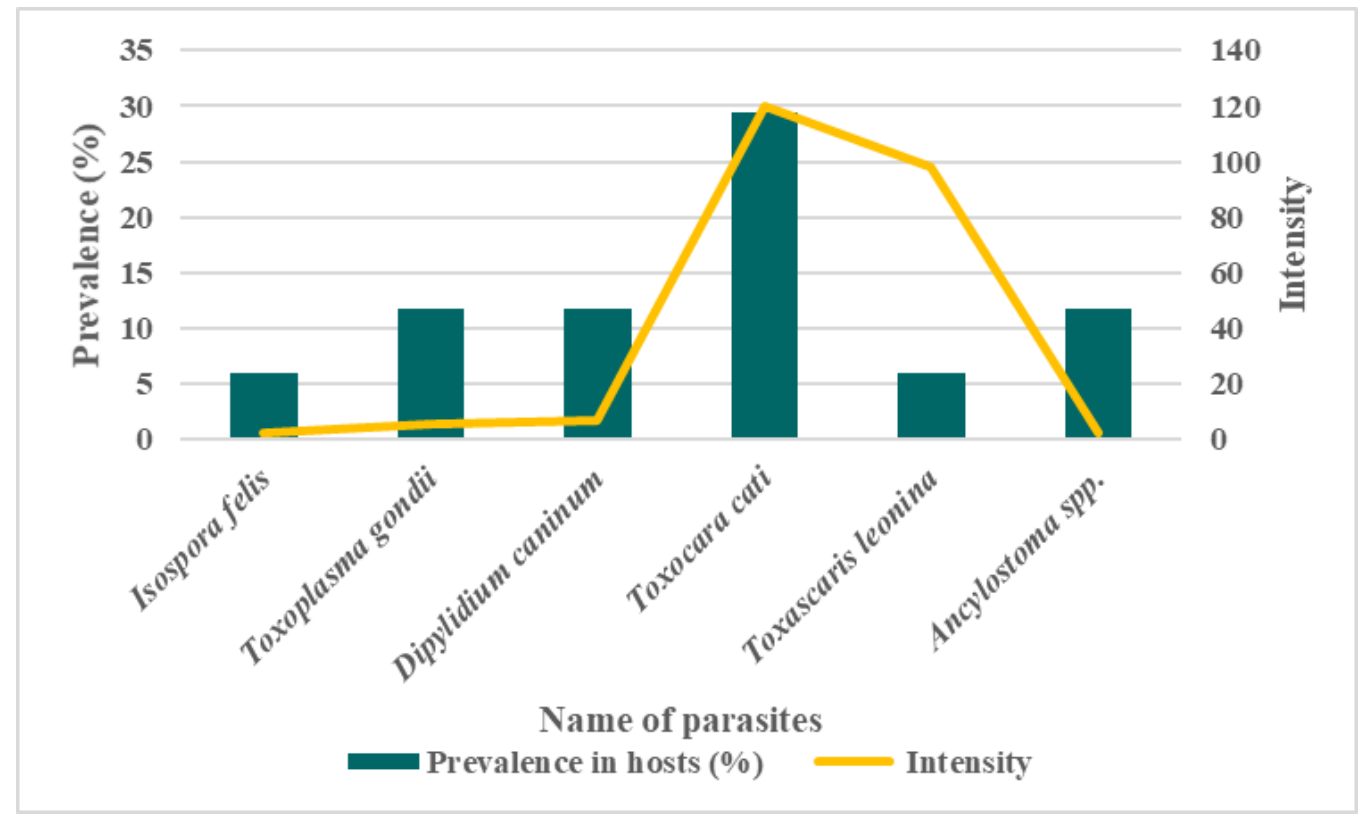

Figure 5. Prevalence and intensity of gastrointestinal parasites in female pet cats.

Table 3. Prevalence and intensity of parasites in relation to seasons in domestic cats.

\begin{tabular}{lcccccc}
\hline Season & $\begin{array}{c}\text { Total no. of } \\
\text { host }\end{array}$ & $\begin{array}{c}\text { No. of host } \\
\text { infected }\end{array}$ & $\begin{array}{c}\text { Prevalence in } \\
\text { hosts }(\%)\end{array}$ & EPG/ CPG & Intensity \pm SD & P value \\
\hline Summer & 8 & 4 & 50.00 & 137 & $34.25 \pm 33.36$ & \\
Monsoon & 10 & 3 & 30.00 & 587 & $195.67 \pm 175.54$ & 0.64 \\
Winter & 12 & 6 & 50.00 & 44 & $7.33 \pm 4.16$ & \\
\hline
\end{tabular}

been collected (Table 3). The prevalence of different gastrointestinal parasites was highest in summer and winter $(50.00 \%)$. The prevalence of parasites was not statistically significant based on seasons $(p=0.64)$. Intensity rate was highest in monsoon (195.67 \pm 175.54$)$, followed by summer $(34.25 \pm 33.36)$ and then winter (7.33 \pm 4.16$)$.

Toxocara cati had the highest prevalence in summer and monsoon, among all the parasites in the three age groups. In winter, Dipylidium caninum had the highest prevalence and intensity rate. The intensity rate of Toxocara cati during summer was the highest among all the parasites in the three seasons, followed by the intensity rate of Ancylostoma spp.in summer (Figures 6 and 7).

\section{DISCUSSION}

The present study has investigated the prevalence and risk factors of gastrointestinal parasites in 30 domestic owned cats from Dhaka Metropolitan City. Also, occurrence of gastrointestinal parasites and awareness of zoonotic diseases among the 26 cat owners have been investigated in this study. In the present study, 43.33\% domestic owned cats $(n=13)$ were infected with one or more species of gastrointestinal parasites. The overall prevalence of the present study is comparable with the findings of Symeonidou et al. (2018), Diakou et al. (2017), Kostopoulou et al. (2017) and Beugnet et al. (2014). They reported that $50.7,35.7,38.1$, and $35.1 \%$ domestic owned cats were infested by gastrointestinal parasites respectively. However, the overall prevalence in the present study was considerably higher than that observed in domestic owned cats by Zottler et al. (2019) (11.7\%) and De Souza et al. (2017) (3.48\%).

In the present investigation, Toxocara cati was the most prevalent parasite $(20 \%, n=6)$ in domestic owned cats (Zottler et al., 2019, Symeonidou et al., 2018, Diakou et al., 2017, Hansen et al., 2017, Szwabe and Blaszkowska, 2017, Beugnet et al., 2014 and Capári et al., 2013. Risk factors of $T$. cati infestation included: outdoor access, frequency of anthelmintic treatment, age and sex. The prevalence of Toxocara cati in the present investigation was similar to the findings of Diakou et al., (2017), Beugnet et al., (2014), Capári et al., (2013 and Zottler et al., (2019) who found that only $3 \%$ of the owned cats were infected 


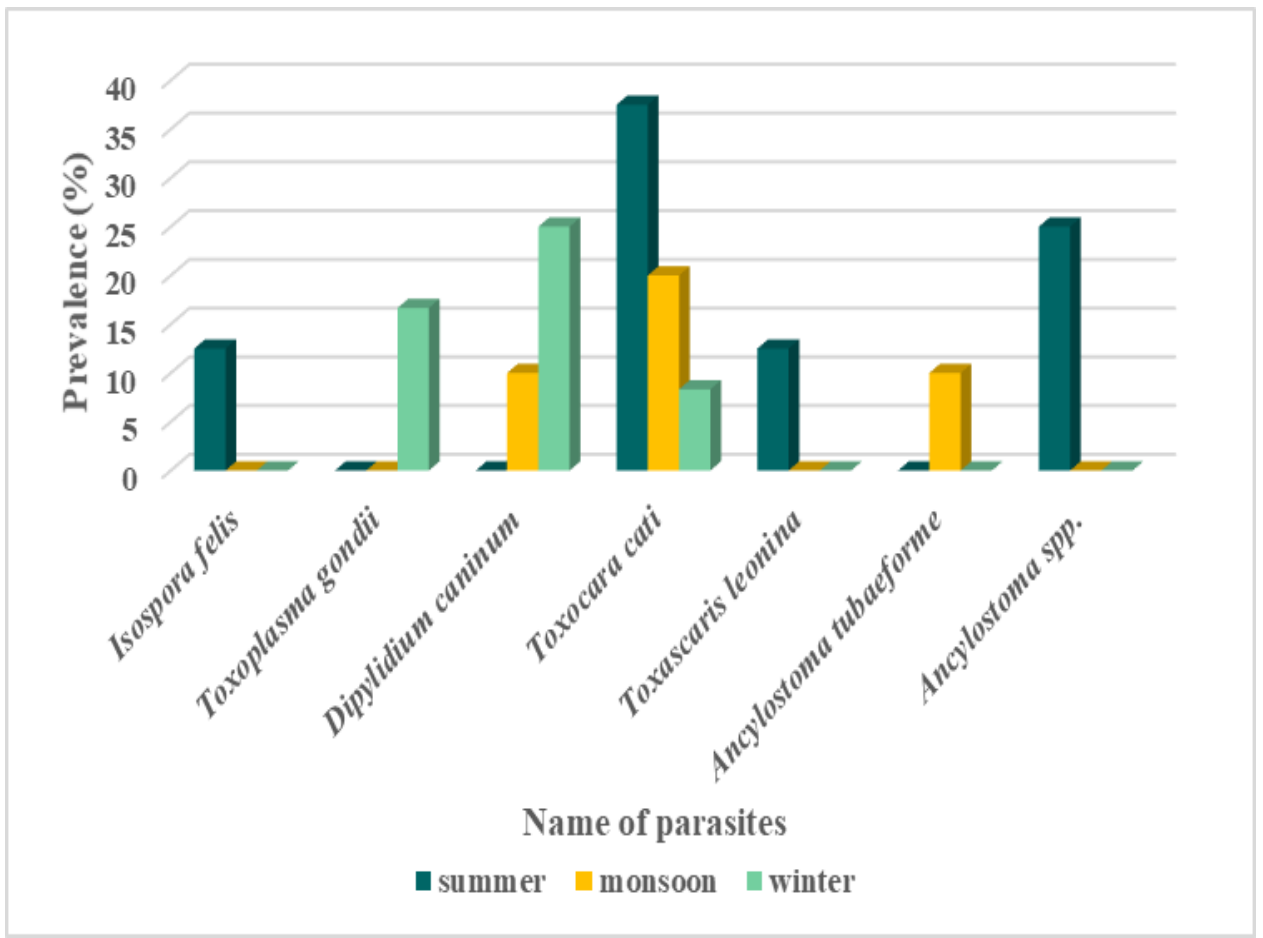

Figure 6. Prevalence of parasites in domestic cats in relation to seasons.

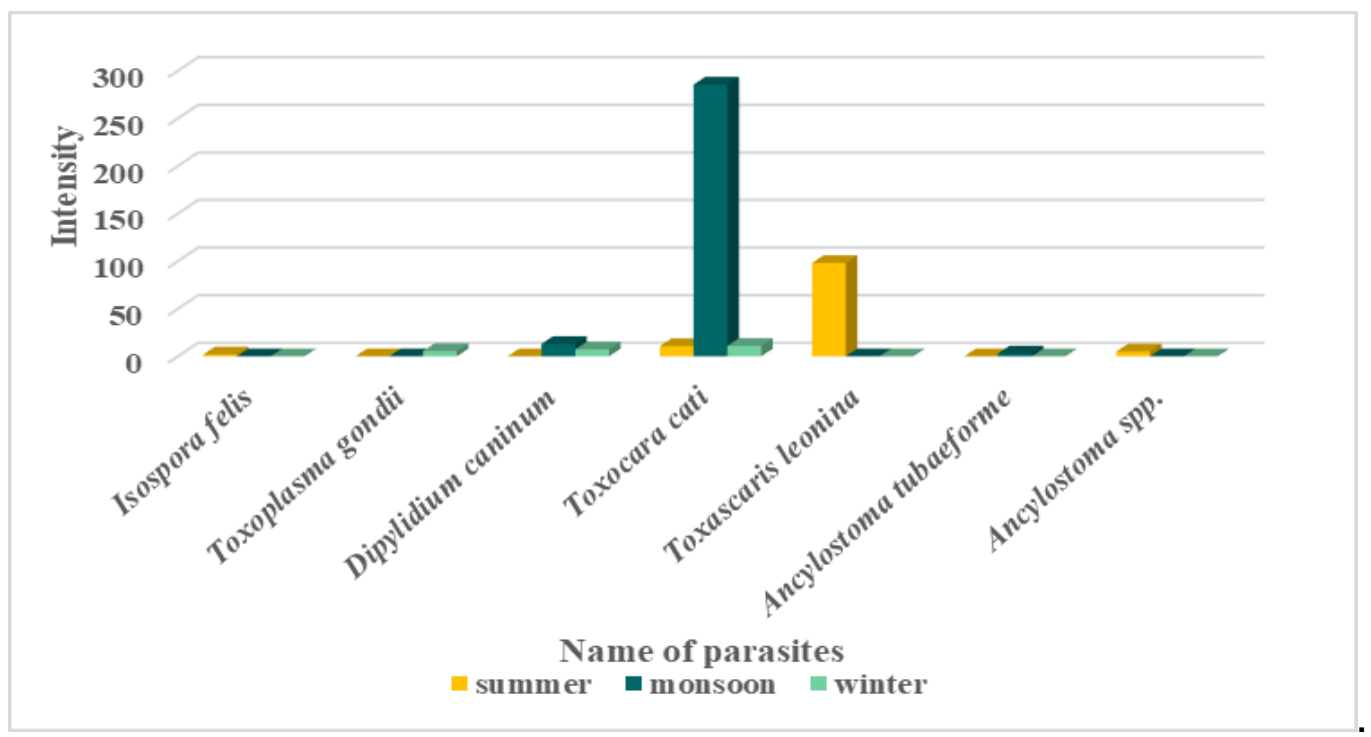

Figure 7. Intensity of parasites in domestic cats in relation to seasons.

with $T$. cati in Switzerland.

Toxocara cati also showed the highest intensity rate $(102.33 \pm 101.61)$ in the present study. It should be mentioned that, among the positive samples, one had a remarkably large number of $T$. cati eggs (558 epg), compared to the others. The owner of this cat mentioned that this cat hunted and ate mice. Toxocara cati is one of the most common gastrointestinal parasites of cats throughout the world (Beugnet et al., 2014).

In the present investigation, risk factors of $T$. cati included outdoor access (50\%). All six of the T. cati infested cats in this study had outdoor access. Symeonidou et al. (2018) also found that the likelihood of $T$. cati infection was higher $(p<0.0001)$ for cats living outdoors in comparison to those living indoors (c.2.7 times, $95 \% \mathrm{Cl}: 1.7-4.1)$. Beugnet et al. (2014) also showed that 
cats with infrequent outdoor access (11.5\%) were significantly less frequently infested with $T$. cati than cats having frequent access (23.0\% positive) to the outdoors. This difference probably reflects differences in feed quality and anthelmintic treatments (Millan and Casanova, 2009). Indeed, indoor cats attract more attention and receive better preventive treatments than outdoor cats. In addition, it may suggest that persistence of $T$. cati eggs in the outdoor environment as well as paratenic hosts playing a crucial role in the transmission of this ascarid (Taylor et al., 2007, Arbabi and Hooshyar, 2009; Hajipour et al., 2016; Rezaiemanesh et al., 2019).

In the present study, it was found that cats receiving no anti-helmintic treatments were more at risk of Toxocara infestation $(57.14 \%)$ than cats receiving 1 or 2 treatments per year (16.67\%) and cats receiving treatment every 3 months (8.33\%). Beugnet et al. (2014) found that cats receiving no treatment were significantly more at risk of Toxocara infestation $(23.3 \%)$ than cats receiving 1 or 2 treatments per year $(22.2 \%)$, while cats receiving more than 3 treatments per year were significantly less infested $(10.4 \%)$ than the previous group. Symeonidou et al. (2018) also found a 1.3-fold higher $(95 \% \mathrm{Cl}: 1-1.7)$ probability for $T$. cati infection for female cats, which, though, was not statistically significant $(p=0.081)$.

Toxascaris leonina, was detected (3.33\%) and showed the second highest intensity rate $(98 \pm 17.89)$. Living outdoors or having access to a garden appears to be a risk factor for $T$. leonina infection in cats. Domestic felines could be more susceptible to infections due to paratenic hosts when they have outdoor access due to their predatory behavior (Zanzani et al., 2014). The prevalence of $T$. leoninai in the present study, was considerably higher than that observed by Symeonidou et al. (2018), Beugnet et al. (2014), Becker et al. (2012) and Näreaho et al. (2012), contrary to the present study, Diakou et al. (2017) reported 7.2 and $8.0 \%$ prevalence of Toxascaris leonina, which is higher than this study.

Dipylidium caninum showed the second highest prevalence $(13.33 \%, n=4)$ in this study. The prevalence of $D$. caninum was considerably higher than that observed by Zottler et al. (2019), Symeonidou et al. (2018), Diakou et al. (2017). De Souza et al. (2017) showed a prevalence of 8.3\% among domestic cats in Brazil. Njuguna et al. (2017) estimated that the prevalence of $D$. caninum was $8.7 \%$ among domestic cats in Kenya. Kanus et al. (2014) reported a prevalence of $23.4 \%$ of dipylidiid cestodes among domestic cats from Tirana, Albania.

The prevalence of Ancylostoma spp. was $6.67 \%(n=2)$ and Ancylostoma tubaeforme was $3.33 \%(n=1)$ in this study. Hookworms have an impact on feline health causing retarded growth and failure to thrive; however, they usually cause subclinical infections. Nevertheless, when heavy parasitism takes place, due to the blood feeding behavior of these nematodes and the resulting ulcerations on the mucosa of the small intestine, severe clinical signs, i.e. haemorrhagic enteritis and anaemia manifest (Kalkofen,
1987). This parasite is a significant public health concern because the migrating larvae of Ancylostoma spp. can cause cutaneous larval migrans following skin penetration. Infective stage larvae of the Ancylostoma spp. hookworm can persist in the environment for several months (Anderson et al., 2003; Center for Disease Control, 2016b; Liotta et al., 2012). The prevalence of hookworm in the present study was similar to that observed by Kostopoulou et al. (2017), Mircean et al. (2010) and Capári et al. (2013. On the other hand, Symeonidou et al. (2018) detected relatively high percentage of the soil-transmitted Ancylostomatidae (16.2\%; $n=186)$.

Risk factors of hookworm infestation in the present investigation included: outdoor access, frequency of antihelmintic treatment, age and season. Also, among kittens $9.09 \%$ and among young cats $20 \%$ were infested by hookworms, but no adult cat was infested in the present study. De Santis et al. (2016) showed age, reproductive status, and season as significant risk factors for hookworm infection. They found that kittens and juveniles were more likely to be infected than geriatric cats, during the summer were more likely to be infected than cats examined during the spring. Also, all the hookworm infested cats showed co-infestation with $T$. cati in the present investigation. Capári et al. (2013) and Knaus et al. (2014) also reported Toxocara and hookworm co-infestation with a prevalence of 1.7 and $3.2 \%$ respectively.

Only two protozoan parasites were detected in the present study, which are Toxoplasma gondii $(6.67 \%, \mathrm{n}=2)$ and Isospora felis $(3.33 \%, \mathrm{n}=1)$. The prevalence of $T$. gondii in the present study is similar to the study of Njuguna et al. (2017) who reported that $7.8 \%$ domestic cats from households in Kenya are infected. Zottler et al. (2019), Kostopoulou et al. (2017) and Barutzki and Schaper (2003) found much lower prevalences of T. gondii in domestic owned cats which are 0.6, 0.4 and $4.5 \%$ respectively. The prevalence of $I$. felis in the present study was similar to that observed by Zottler et al. (2019), Diakou et al. (2017), Hansen et al. (2017) and Wyrosdick et al. (2017) who showed that 3, 2.5, 3.1 and $1.3 \%$ domestic owned cats are infected in Switzerland, Cyprus, Denmark and Florida respectively. Beugnet et al. (2014) reported that $9.7 \%$ of domestic owned cats from Europe are infected with Cystoisospora spp. All of the T. gondii and $I$. felis infected cats in the present study were kittens and young cats. According to Beugnet et al. (2014), young cats are estimated to be much more frequently infested with protozoans than adult cats. Mircean et al. (2010) reported in their study that most of the $T$. gondii oocyst spontaneous shedding cats were younger than 6 months of age.

The intensity rate of $T$. gondii in this study was $5.5 \pm 1.45$. Diagnosis of toxoplasmosis by microscopy in feline populations is difficult due to this parasite's short shedding period (Cook et al. 2010). Cats (and wild felids) are the only source responsible for environmental contamination of $T$. gondii oocysts. $T$. gondii is a highly prevalent zoonosis worldwide and poses serious health risk for 
immunocompromised individuals and for foetuses during primary infections in women (Zottler et al. 2019). Cats only shed Toxoplasma oocysts once during their lifetime, and only during a limited period of time (2 to 3 weeks). After oocysts are passed in the faeces, they must mature for between 2 and 5 days before they are infective for humans and other animals (Angulo et al. 1994, Robertson et al. 2000). Therefore, the risk of acquiring toxoplasmosis from freshly passed cat faeces while cleaning a litter box would appear to be extremely low. Nevertheless, daily cleaning of cat litter trays is suggested to ensure that when Toxoplasma oocysts are shed they have no time to sporulate and become infective, and wearing gloves while cleaning the trays have been recommended, particularly in high risk groups (Borthakur and mukharjee, 2011; Coati and schnieder, 2004.).

In the present observation, Ascaris lumbricoides was the only parasite found in cat owners, which had a prevalence of $11.54 \%$ and its intensity rate was $5.67 \pm 2.04$. The parasite community of cat owners has not been covered in this study. The samples of the cat owners were collected simultaneously with the cats. Results showed that among 26 cat owners, seven take anti-helminthics medicines once every 6 months, ten take once a year, five rarely takes anti-helminthic medicines and four cat owners cited that they did not take any anti-helminthic medicines. Association between frequency of taking anti-helminthic medicine and prevalence of parasitic infection in cat owners was found significant $(p \leq 0.05)$.

Only $40 \%$ of the cat owners participating in the present study were aware about zoonotic diseases. Among them, only $13.33 \%$ were aware about zoonotic intestinal helminths, rabies $(30 \%)$ and toxoplasmosis $(20 \%)$ were the most cited example. In a study on pet owner awareness about zoonotic diseases in Qatar, Alho et al. (2018) reported dermatophytosis (ringworm) (21.3\%), rabies $(16 \%)$ and toxoplasmosis $(7.3 \%)$ were the most cited examples. Matos et al. (2015) found scabiesmites/sarcoptic mange (86.9\%), followed by leishmaniasis $(83 \%)$ and toxoplasmosis $(64.7 \%)$ as the three most frequently identified zoonotic diseases by pet owners in Portugal. In a study in Northern Italy, Zanzani et al. (2014) found that when asked about human health risks due to canine and feline intestinal parasites, $49.19 \%$ showed awareness of the occurrence, $35.67 \%$ answered that no risk is given, and $15.14 \%$ declared they had even never considered such probability. This shows that awareness of zoonotic disease is very low in the present investigation which might be one of the causes behind the high prevalence of gastrointestinal parasites in domestic owned cats in this study.

In summary, the present study indicates a high prevalence of endoparasite infections in owned domestic cats in Dhaka metropolitan city, which was influenced by frequency of anti-helminthic medicine given $(p=0.001)$, access to the outdoors (0.004) and type of household $(p=0.03)$. It should be mentioned that in Bangladesh, many cat owners cannot afford preventive measures and act only when there is a life-threatening problem affecting their animals. According to McGlade et al. (2003), for each antihelminthic treatment given in a year, the risk of parasitism decreased by 0.2 times $(\mathrm{Cl} 0.1-0.5)$ and for each cat present in a household the risk of parasitism increased by 1.3 times $(\mathrm{Cl} 1.1-1.5)$. Also, in the present study, $75 \%$ of the cats with outdoor access were infected with parasites compared to only $22.22 \%$ among those who did not have outdoor access. Pereira et al. (2018) reported that cats living outdoors had an increased risk of infection in comparison to indoor cats (OR 13.150; Cl 3.37-51.01). A study by Zanzani et al. (2014) had pointed out that the overall prevalence of intestinal parasites in household cats is statistically significantly higher than cats that lived outside or had access to a garden.

\section{Conclusion}

Overall, these results indicated that cat owners needed more and clear information about zoonotic potential of intestinal parasites. Many of the parasites identified in the domestic owned cats in the present study have zoonotic potential. The presence of felid parasitism in domestic owned cats depends on the level of awareness among owners, and it is therefore important to educate cat owners and increase their perception of the risks involved. It is important that veterinarians educate their clients on the importance of taking appropriately timed prophylactic measures in order to prevent an increase in the prevalence of parasite infection in domestic owned cats and zoonoses. Domestic cats population is growing all over the world, perhaps because they are well adapted to a modern lifestyle. As cats moved from pet to family member, care for their health became a family concern. Despite the benefits that animals offer to people, potential health hazards also exist and allowing the transmission of pathogens that are accessible to other animals and people sharing the environment.

\section{CONFLICT OF INTEREST}

The authors declare that they have no conflict of interest

\section{REFERENCES}

Alho, A. M., Lima, C., Colella, V., de Carvalho, L. M., Otranto, D., \& Cardoso, L. (2018). Awareness of zoonotic diseases and parasite control practices: a survey of dog and cat owners in Qatar. Parasites \& vectors, 11, Article number 133.

Anderson, T. C., Foster, G. W., \& Forrester, D. J. (2003). Hookworms of feral cats in Florida. Veterinary Parasitology, 115(1), 19-24.

Angulo, F. J., Glaser, C. A., Juranek, D. D., Lappin, M. R., \& Regnery, R. L. (1994). Caring for pets of immunocompromised persons. Journal of the American Veterinary Medical Association, 205(12), 1711-1718. 
Arbabi, M., \& Hooshyar, H. (2009). Gastrointestinal parasites of stray cats in Kashan, Iran. Tropical Biomedicine, 26(1), 16-22.

Baneth, G., Thamsborg, S. M., Otranto, D., Guillot, J., Blaga, R., Deplazes, P., \& Solano-Gallego, L. (2016). Major parasitic zoonoses associated with dogs and cats in Europe. Journal of Comparative Pathology, 155(1), S54-S74.

Barutzki, D., \& Schaper, R. (2003). Endoparasites in dogs and cats in Germany 1999-2002. Parasitology Research, 90(3), S148-S150.

Bernstein, P. L. (2007). The human-cat relationship. In: The welfare of cats (pp. 47-89). Springer, Dordrecht.

Beugnet, F., Bourdeau, P., Chalvet-Monfray, K., Cozma, V., Farkas, R., Guillot, J., Halos, L., Joachim, A., Losson, B., Miró, G., \& Otranto, D. (2014). Parasites of domestic owned cats in Europe: co-infestations and risk factors. Parasites \& Vectors, 7 Article number 291.

Borthakur, S. K., \& Mukharjee, S. N. (2011). Gastrointestinal helminthes in stray cats (Felis catus) from Aizawl, Mizoram, India. Southeast Asian Journal of Tropical Medicine and Public Health, 42(2), 255-258.

Capári, B., Hamel, D., Visser, M., Winter, R., Pfister, K., \& Rehbein, S. (2013). Parasitic infections of domestic cats, Felis catus, in western Hungary. Veterinary Parasitology, 192(1-3), 33-42.

Center for Disease Control (2016a). Toxocariasi. Retrieved 15th June, 2016 from https://www.cdc.gov/dpdx/toxocariasis/index.html.

Center for Disease Control (2016b). Zoonotic hookworm epidemiology and risk factors. Retrieved 15th June, 2016 from https://www.cdc.gov/parasites/hookworm/index.html.

Cheesbrough, M. (1987). Medical laboratory manual for tropical countries. 2nd edition. Tropical Health Technology, London, Boston, Butterworks. 13, 3-5.

Coati, N., Schnieder, T., \& Epe, C. (2004). Vertical transmission of Toxocara cati Schrank 1788 (Anisakidae) in the cat. Parasitology Research, 92(2), 142-146.

Cook, A. J. C., Holliman, R., Gilbert, R. E., Buffolano, W., Zufferey, J., Petersen, E., Jenum, P. A., Foulon, W., Semprini, A. E., \& Dunn, D. T. (2000). Sources of toxoplasma infection in pregnant women: European multicentre case-control study Commentary: Congenital toxoplasmosis-further thought for food. BMJ, 321(7254), 142-147.

Diakou, A., Sofroniou, D., Di Cesare, A., Kokkinos, P., \& Traversa D. (2017). Occurrence and zoonotic potential of endoparasites in cats of Cyprus and a new distribution area for Troglostrongylus brevior. Parasitology Research, 116(12), 3429-3435.

Driscoll, C. A., Clutton-Brock, J., Kitchener, A. C. \& O'brien, S. J. (2009). The taming of the cat. Scientific American, 300(6), 6875.

Duarte, A. M., Jenkins, T. P., Latrofa, M. S., Giannelli, A., Papadopoulos, E., de Carvalho, L. M., Nolan, M. J., Otranto, D., \& Cantacessi, C. (2016). Helminth infections and gut microbiota-a feline perspective. Parasites \& vectors, 9, Article Number 625.

Deplazes, P., van Knapen, F., Schweiger, A., \& Overgaauw, P. A. (2011). Role of pet dogs and cats in the transmission of helminthic zoonoses in Europe, with a focus on echinococcosis and toxocarosis. Veterinary parasitology, 182(1), 41-53.

De Santis, A. C., Raghavan, M., Caldanaro, R. J., Glickman, N. W., Moore, G. E., Lewis, H. B., ... \& Glickman, L. T. (2006). Estimated prevalence of nematode parasitism among pet cats in the United States. Journal of the American Veterinary Medical Association, 228(6), 885-892.
De Souza, F. B., Nakiri, I. M., de Oliveira Lourenço, N., da Silva, G. G., Paschoalini, D. R., Guimarães-Okamoto, P. T. C., \& Melchert, A. (2017). Prevalence of intestinal endoparasites with zoonotic potential in domestic cats from Botucatu, SP, Brazil. Topics in companion animal medicine, 32(3), 114-117.

ESCCAP (2017). Worm control in dogs and cats. In: ESCCAP Guidelines. ESCCAP. Accessed July 2017.

Giannelli, A., Capelli, G., Joachim, A., Hinney, B., Losson, B., Kirkova, Z., René-Martellet, M., Papadopoulos, E., Farkas, R. Napoli, E., \& Brianti, E. (2017). Lungworms and gastrointestinal parasites of domestic cats: A European perspective. International Journal for Parasitology, 47(9), 517528.

Hajipour, N., Baran, A. I., Yakhchali, M., Khojasteh, S. M. B., Hesari, F. S., Esmaeilnejad, B., \& Arjmand, J. (2016). A survey study on gastrointestinal parasites of stray cats in Azarshahr (East Azerbaijan province, Iran). Journal of Parasitic Diseases, 40(4), 1255-1260.

Hansen, A. P., Skarbye, L. K., Vinther, L. M., Willesen, J. L., Pipper, C. B., Olsen, C. S., \& Mejer, H. (2017). Occurrence and clinical significance of Aelurostrongylus abstrusus and other endoparasites in Danish cats. Veterinary Parasitology, 234, 31-39.

Hoopes, J., Hill, J. E., Polley, L., Fernando, C., Wagner, B., Schurer, J., \& Jenkins, E. (2015). Enteric parasites of freeroaming, owned, and rural cats in prairie regions of Canada. The Canadian Veterinary Journal, 56(5), 495-501.

Kalkofen, U. P. (1987). Hookworms of dogs and cats. Veterinary Clinics of North America: Small Animal Practice, 17(6), 13411354.

Kaye, A. E., Belz, J. M., \& Kirschner R. E. (2007). Pediatric Dog Bite Injuries: A 5-year review of the experience at the children's hospital of Philadelphia. 76th annual conference of the american-society-of-plastic-surgeons. Pp. 29-30.

Khalafalla, R. E. (2011). A survey study on gastrointestinal parasites of stray cats in Northern Region of Nile Delta, Egypt. PLoS ONE. 6(7), e20283.

Knaus, M., Rapti, D., Shukullari, E., Kusi, I., Postoli, R., Xhaxhiu, D., Silaghi, C., Hamel, D., Visser, M., Winter, R., \& Rehbein, S. (2014). Characterisation of ecto-and endoparasites in domestic cats from Tirana, Albania. Parasitology Research, 113(9), 3361-3371.

Kostopoulou, D., Claerebout, E., Arvanitis, D., Ligda, P., Voutzourakis, N., Casaert, S., \& Sotiraki, S. (2017). Abundance, zoonotic potential and risk factors of intestinal parasitism amongst dog and cat populations: The scenario of Crete, Greece. Parasites \& vectors, 10, Article Number 43.

Krause-Parello, C. A. (2008). The mediating effect of pet attachment support between loneliness and general health in older females living in the community. Journal of Community Health Nursing, 25(1), 1-14.

Macpherson, C. N. (2005). Human behaviour and the epidemiology of parasitic zoonoses. International Journal for Parasitology, 35(11-12), 1319-1331.

Matos, M., Alho, A. M., Owen, S. P., Nunes, T., \& de Carvalho, L. M. (2015). Parasite control practices and public perception of parasitic diseases: a survey of dog and cat owners. Preventive Veterinary medicine, 122(1-2), 174-180.

McGlade, T. R., Robertson, I. D., Elliot, A. D., Read, C., \& Thompson, R. C. A. (2003). Gastrointestinal parasites of domestic cats in Perth, Western Australia. Veterinary Parasitology, 117(4), 251-262.

McNamara, J., Drake, J., Wiseman, S., \& Wright, I. (2018). Survey of European pet owners quantifying endoparasitic 
infection risk and implications for deworming recommendations. Parasites \& vectors, 11, Article Number 571.

McNicholas, J., Gilbey, A., Rennie, A., Ahmedzai, S., Dono, J. A., \& Ormerod, E. (2005). Pet ownership and human health: a brief review of evidence and issues. BMJ, 331(7527), 1252-1254.

Mircean, V., Titilincu, A., \& Vasile, C. (2010). Prevalence of endoparasites in household cat (Felis catus) populations from Transylvania (Romania) and association with risk factors. Veterinary Parasitology, 171(1-2), 163-166.

Näreaho, A., Puomio, J., Saarinen, K., Jokelainen, P., Juselius, T., \& Sukura, A. (2012). Feline intestinal parasites in Finland: Prevalence, risk factors and anthelmintic treatment practices. Journal of Feline Medicine and Surgery, 14(6), 378-383.

Njuguna, A. N., Kagira, J. M., Karanja, S. M., Ngotho, M., Mutharia, L., \& Maina, N. W. (2017). Prevalence of Toxoplasma gondii and other gastrointestinal parasites in domestic cats from households in Thika region, Kenya. BioMed Research International, Volume 2017, Article ID 7615810, 6 pages.

Otranto, D., Cantacessi, C., Dantas-torres, F., Brianti, E., Pfeffer, M., G, C., Guberti, V., Capelli, G., \& Deplazes, P. (2015). The role of wild canids and felids in spreading parasites to dogs and cats in Europe, part II: Helminths and arthropods. Veterinary Parasitology, 213 (1-2), 24-37.

Pereira, N. W. B., Chiconini, M., Leonel, J. A. F., Benassi, J. C., Ruiz, V. L. D. A., Keid, L. B., ... \& Oliveira, T. M. F. D. S. (2018). Occurrence of infectious and parasitic diseases in association with the outdoor habits of household dogs and cats a casecontrol study. Ars Veterinaria, 34(3), 124-128.

Qureshi, A. I., Memon, M. Z., Vazquez, G., \& Suri, M. F. K. (2009). Cat ownership and the Risk of Fatal Cardiovascular Diseases. Results from the Second National Health and Nutrition Examination Study Mortality Follow-up Study. Journal of vascular and interventional neurology, 2(1), 132-135.

Rezaiemanesh, M. R., Afzalaghaee, M., Hamidi, S., Eshaghzadeh, A., Paydar, M., \& Hejazi, S. H. (2019). Prevalence of toxocariasis and its related risk factors in humans, dogs and cats in northeastern Iran: a populationbased study. Transactions of The Royal Society of Tropical Medicine and Hygiene, 113(7), 399-409.

Riggio, F., Mannella, R., Ariti, G., \& Perrucci, S. (2013). Intestinal and lung parasites in owned dogs and cats from central Italy. Veterinary Parasitology, 193(1-3), 78-84.
Soulsby, E. J. L. 1982. Helminths, arthropods and protozoa of domesticated animals. 7th edition. Baillire Tindall and Cassell Ltd, London. 792 pp.

Symeonidou, I., Gelasakis, A. I., Arsenopoulos, K., Angelou, A., Beugnet, F., \& Papadopoulos, E. (2018). Feline gastrointestinal parasitism in Greece: emergent zoonotic species and associated risk factors. Parasites \& vectors, 11, Article Number 227.

Szwabe, K., \& Blaszkowska, J. (2017). Stray dogs and cats as potential sources of soil contamination with zoonotic parasites. Annals of Agricultural and Environmental Medicine, 24(1), 39-43.

Taylor, M. A., Coop, R. L., \& Wall, R. L. (2007). Veterinary Parasitology. 3rd edition. Blackwell Publishing Ltd, Oxford.

Traversa, D. (2012). Pet roundworms and hookworms: A continuing need for global worming. Parasites \& Vectors, 5, Article Number 91.

Vigne, J. D., Guilaine, J., Debue, K., Haye, L., \& Gérard, P. (2004). Early taming of the cat in Cyprus. Science, 304(5668), 259-259.

Wong, S. K., Feinstein, L. H., \& Heidmann, P. (1999). Healthy pets, healthy people. Journal of the American Veterinary Medical Association, 215(3), 335-338.

Wyrosdick, H. M., Chapman, A., Martinez, J., \& Schaefer, J. J. (2017). Parasite prevalence survey in shelter cats in Citrus County, Florida. Veterinary Parasitology: Regional Studies and Reports, 10, 20-24.

Yang, Y., \& Liang, H. (2015). Prevalence and risk factors of intestinal parasites in cats from China. BioMed Research International, Volume 2015, Article ID 967238, 5 pages.

Zanzani, S. A., Gazzonis, A. L., Scarpa, P., Berrilli, F., \& Manfredi, M. T. (2014). Intestinal parasites of owned dogs and cats from metropolitan and micropolitan areas: Prevalence, zoonotic risks, and pet owner awareness in northern Italy. BioMed Research International, Volume 2014, Article ID 696508, 10 pages.

Zottler, E. M., Bieri, M., Basso, W., \& Schnyder, M. (2019). Intestinal parasites and lungworms in stray, shelter and privately owned cats of Switzerland. Parasitology international, 69, 75-81. 